\title{
Influences of refrigerant-based nanofluid composition and heating condition on the migration of nanoparticles during pool boiling. Part I: Experimental measurement
}

\author{
Hao Peng ${ }^{a, b}$, Guoliang Ding ${ }^{a, *}$, Haitao $\mathrm{Hu}^{a}$ \\ a Institute of Refrigeration and Cryogenics, Shanghai Jiaotong University, 800 Dongchuan Road, Shanghai 200240, PR China \\ ${ }^{\mathrm{b}}$ Key Laboratory of Microgravity (National Microgravity Laboratory)/CAS, Institute of Mechanics, Chinese Academy of Sciences (CAS), \\ 15 Beisihuan Xilu, Beijing 100190, PR China
}

A R T I C L E I N F O

Article history:

Received 8 February 2011

Received in revised form

8 July 2011

Accepted 28 July 2011

Available online 4 August 2011

Keywords:

Heat flux

Oil

Particle

Pool boiling

Refrigerant

\begin{abstract}
A B S T R A C T
Influences of refrigerant-based nanofluid composition and heating condition on the migration of nanoparticles during pool boiling were investigated experimentally. The nanoparticles include $\mathrm{Cu}$ (average diameters of 20,50 and $80 \mathrm{~nm}$ ), $\mathrm{Al}$ and $\mathrm{Al}_{2} \mathrm{O}_{3}$ (average diameters of $20 \mathrm{~nm}$ ), and CuO (average diameter of $40 \mathrm{~nm}$ ). The refrigerants include R113, $\mathrm{R} 141 \mathrm{~b}$ and $\mathrm{n}$-pentane. The mass fraction of lubricating oil RB68EP is from 0 to $10 \mathrm{wt} \%$, the heat flux is from 10 to $100 \mathrm{~kW} \mathrm{~m}^{-2}$, and the initial liquid-level height is from 1.3 to $3.4 \mathrm{~cm}$. The experimental results show that the migration ratio of nanoparticles during the pool boiling of refrigerant-based nanofluid increases with the decrease of nanoparticle density, nanoparticle size, dynamic viscosity of refrigerant, mass fraction of lubricating oil or heat flux; while increases with the increase of liquid-phase density of refrigerant or initial liquid-level height.
\end{abstract}

(c) 2011 Elsevier Ltd and IIR. All rights reserved.

\section{Influences de la composition et le chauffage d'un nanofluide sur la migration des nanoparticules lors de l'ébullition libre. Partie I : mesures expérimentales}

Mots clés : Flux thermique ; Huile ; Particule ; Ébullition libre ; Frigorigène

\section{Introduction}

Refrigerant-based nanofluid is a new type of heat transfer working fluid by dispersing nanoparticles in conventional pure refrigerant, and is also called as nanorefrigerant by some researchers (Ding et al., 2009; Jiang et al., 2009). The existing researches show that substituting refrigerant-based nanofluid for conventional refrigerant is an effective method for

\footnotetext{
* Corresponding author. Tel.: +86 21 34206378; fax: +86 2134206814 .

E-mail address: glding@sjtu.edu.cn (G. Ding).

0140-7007/\$ - see front matter @ 2011 Elsevier Ltd and IIR. All rights reserved.

doi:10.1016/j.ijrefrig.2011.07.010
} 


\begin{tabular}{|c|c|c|c|}
\hline \multicolumn{2}{|c|}{ Nomenclature } & $\bar{u}$ & average velocity of bubbles \\
\hline$d$ & diameter of single nanoparticle (m) & $x$ & mass fraction of lubricating oil \\
\hline$k_{\mathrm{B}}$ & Boltzmann constant, $k_{\mathrm{B}}=1.381 \times 10^{-23} \mathrm{~J} \mathrm{~K}^{-1}$ & \multicolumn{2}{|c|}{ Greek symbols } \\
\hline$L$ & initial liquid-level height (m) & $\gamma$ & surface tension of liquid $\left(\mathrm{N} \mathrm{m}^{-1}\right)$ \\
\hline$m$ & mass $(\mathrm{kg})$ & $\zeta$ & migration ratio of nanoparticles \\
\hline$m_{\mathrm{b}}$ & mass of bubbles (kg) & $\varphi$ & initial nanoparticle concentration \\
\hline & heat flux $\left(\mathrm{W} \mathrm{m}^{-2}\right)$ & $\rho$ & density $\left(\mathrm{kg} \mathrm{m}^{-3}\right)$ \\
\hline \multirow{2}{*}{\multicolumn{4}{|c|}{$\begin{array}{l}R\left(u>u_{0, \min }\right) \text { ratio of number of nanoparticles with velocity } \\
\text { larger than } u_{0, \min } \text { to the total number of }\end{array}$}} \\
\hline & & $\mathrm{L}$ & liquid-phase \\
\hline & temperature $(\mathrm{K})$ & $\mathrm{n}$ & nanoparticle \\
\hline \multirow{2}{*}{$\begin{array}{l}T \\
u \\
u_{0, \min }\end{array}$} & velocity of single nanoparticle $\left(\mathrm{m} \mathrm{s}^{-1}\right)$ & 0 & lubricating oil \\
\hline & minimum escaping velocity $\left(\mathrm{m} \mathrm{s}^{-1}\right)$ & $\mathrm{r}$ & refrigerant \\
\hline
\end{tabular}

improving the energy efficiency of refrigeration system (Wang et al., 2003; Wang et al., 2007; Bi et al., 2008). In order to apply the refrigerant-based nanofluid in the refrigeration system, the phase-change heat transfer characteristics of refrigerantbased nanofluid should be quantitatively evaluated, and the cycle behavior of nanoparticles in the refrigeration system should be known. The phase-change heat transfer characteristics of refrigerant-based nanofluid is affected by the distribution of nanoparticle concentration in the liquid-phase and vapor-phase refrigerant because the distribution of nanoparticle concentration has significant effect on the thermophysical properties of the liquid-phase and vaporphase refrigerant. Meanwhile, the cycle behavior of nanoparticles in the refrigeration system is also affected by the distribution of nanoparticle concentration. Therefore, the migration characteristics of nanoparticles between liquidphase and vapor-phase need be known to determine the distribution of nanoparticle concentration in the liquid-phase and vapor-phase refrigerant. As the pool boiling heat transfer is the basic type of phase-change heat transfer, the migration characteristics of nanoparticles from liquid-phase to vaporphase during the pool boiling process of refrigerant-based nanofluid should be firstly investigated.

In recent years, some researchers have experimentally investigated the pool boiling heat transfer characteristics of refrigerant-based nanofluids (Kedzierski, 2009; Kedzierski and Gong, 2009; Trisaksri and Wongwises, 2009; Peng et al., 2010) and flow boiling heat transfer characteristics of refrigerantbased nanofluids (Peng et al., 2009; Henderson et al., 2010). Some of the researches indicate that the presence of nanoparticles can enhance the boiling heat transfer (Kedzierski, 2009; Kedzierski and Gong, 2009; Peng et al., 2009; Peng et al., 2010), while the other researches indicate that the presence of nanoparticles deteriorates the boiling heat transfer (Trisaksri and Wongwises, 2009; Henderson et al., 2010). From these researches, it can be seen that the nanoparticle type, the nanoparticle size, the refrigerant type, the mass fraction of lubricating oil and the heat flux have influences on the pool boiling heat transfer of refrigerant-based nanofluid. Therefore, the influences of the above factors on the migration characteristics of nanoparticles during the pool boiling process of refrigerant-based nanofluid should be investigated. In addition, the initial liquid-level height affects the pool boiling heat transfer, so the influence of initial liquid-level height on the migration characteristics of nanoparticles also needs to be investigated.

Compared with the researches on the boiling heat transfer of refrigerant-based nanofluid, there are much fewer researches on the migration characteristics of nanoparticles. A literature survey shows that the migration characteristics of nanoparticles during the pool boiling process of refrigerantbased nanofluid is only reported by Ding et al. (2009). In that paper, the relationship between the migration ratio and the volume fraction of nanoparticles was investigated. However, only one type of nanoparticle and one type of refrigerant were used in the experiments at a fixed heat flux. In order to well understand the migration characteristics of nanoparticles, more experiments concerning the influences of nanoparticle type, nanoparticle size, refrigerant type, mass fraction of lubricating oil, heat flux and initial liquid-level height on the migration characteristics of nanoparticles are needed.

The objective of this study is to experimentally investigate the influences of refrigerant-based nanofluid composition (including nanoparticle type, nanoparticle size, refrigerant type and mass fraction of lubricating oil) and heating condition (including heat flux and initial liquid-level height) on the migration characteristics of nanoparticles, and to propose a model to predict the migration ratio of nanoparticles. Part I of the present study focuses on the experimental measurement, and part II focuses on the model development.

\section{Experimental facility and method}

\subsection{Experimental facility}

The experimental facility used for testing the migration characteristics of nanoparticles in the refrigerant-based nanofluid pool boiling consists of three parts (i.e., a pool boiling apparatus, a migrated mass measurement apparatus and a capture cover), as schematically shown in Fig. 1. The pool boiling apparatus mainly consists of a boiling vessel and an electric heating membrane. The boiling vessel is a cylindrical glass container with the inside diameter of $50 \mathrm{~mm}$ and the height of $95 \mathrm{~mm}$. The vessel is insulated with glass fibers to reduce heat loss to the surroundings. The electric heating 


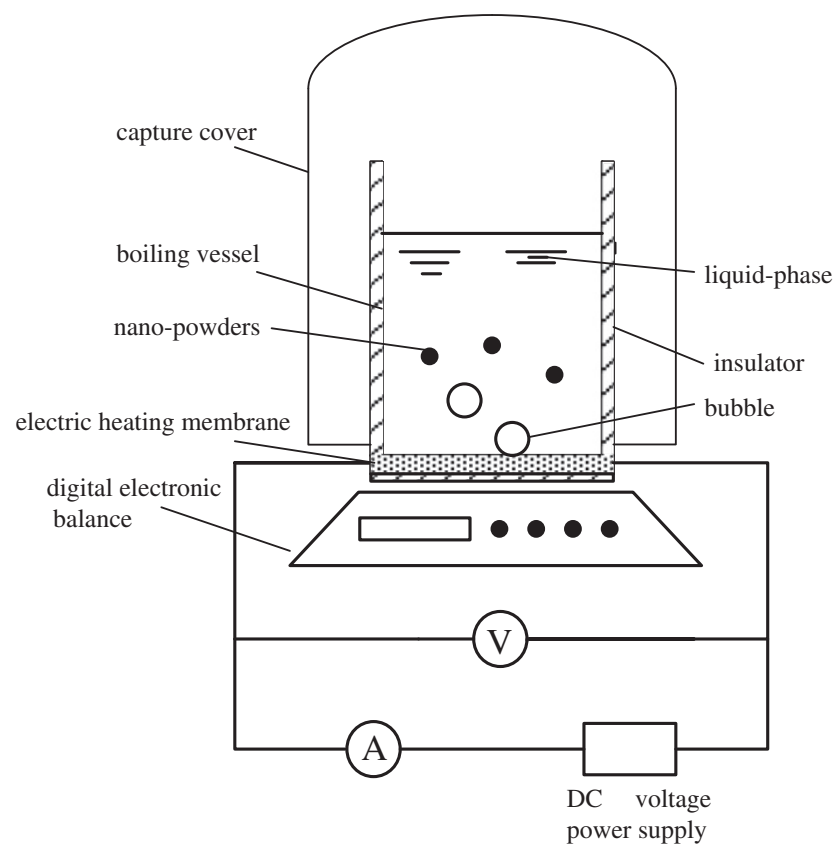

Fig. 1 - Experimental facility.

membrane is made of indium tin oxide (ITO) film, and is connected with the direct-current voltage power supply. The ampere meter with the calibrated precision of $0.5 \%$ is used for reading electric current supplied to the heating surface, and a data acquisition system with the calibrated precision of $0.002 \%$ is used to measure the voltage across the heating surface. The heat flux through the heating surface is controlled by adjusting the heating power of the electric heating membrane, and is calculated by the measured electric current, voltage and heating surface area. The uncertainty of heat flux is estimated to be smaller than $1.2 \%$. The migrated mass measurement apparatus is a digital electronic balance with a measurement range of $10.0 \mathrm{mg}-210.0000 \mathrm{~g}$ and a maximum error of $0.1 \mathrm{mg}$. The capture cover is used to capture the spouted nanoparticles, preventing the possible environmental contamination caused by the nanoparticles.

\subsection{Experimental method}

All the experiments are performed at atmospheric pressure $(101.3 \mathrm{kPa})$ by venting the boiling vessel to ambient. The migrated mass of nanoparticles is obtained by the weighing method proposed by Ding et al. (2009).

In the experiments for the refrigerant-based nanofluid without lubricating oil, the experimental procedure consists of the following steps: 1) adding nanoparticles with the original mass of $m_{n o}$ to the boiling vessel; 2) weighing the total mass of the boiling vessel and the nanoparticles, $m_{1}$; 3 ) adding the refrigerant with the original mass of $m_{\mathrm{ro}}$ to the boiling vessel; 4) opening the direct-current voltage power supply and heating the refrigerant-based nanofluid to be boiling; 5) adjusting the voltage to control the heat flux; 6) weighing the total mass of the boiling vessel and the nanoparticles, $m_{2}$, when the refrigerant is entirely evaporated (the signal for the entire evaporation is that the mass of mixture does not change for $12 \mathrm{~h}$ ); 7) calculating the migrated mass of nanoparticles with the equation $\Delta m_{\mathrm{n}}=m_{1}-m_{2}$.

In the experiments for the refrigerant-based nanofluid with lubricating oil, the experimental procedure consists of the following steps: 1 ) adding nanoparticles with the original mass of $m_{\mathrm{no}}$ and the lubricating oil with the mass of $m_{\mathrm{o}}$ to the boiling vessel; 2) weighing the total mass of the boiling vessel, the nanoparticles and the lubricating oil, $\left.m_{3} ; 3\right)$ adding the refrigerant with the original mass of $m_{\mathrm{r} 0}$ to the boiling vessel; 4) opening the direct-current voltage power supply and heating the refrigerant-based nanofluid with lubricating oil to be boiling; 5) adjusting the voltage to control the heat flux; 6) weighing the total mass of the boiling vessel, the nanoparticles and the lubricating oil, $m_{4}$, when the refrigerant is entirely evaporated (the signal for the entire evaporation is that the mass of mixture does not change for $12 \mathrm{~h}$ ); 7) calculating the migrated mass of nanoparticles with the equation $\Delta m_{\mathrm{n}}=m_{3}-m_{4}$.

\subsection{Experimental objects}

The nanoparticles used in the present study include commonly used metal nanoparticles (i.e., $\mathrm{Cu}$ and $\mathrm{Al}$ ) and metal oxide nanoparticles (i.e., $\mathrm{CuO}$ and $\mathrm{Al}_{2} \mathrm{O}_{3}$ ). Cu nanoparticles have three different average diameters $\left(d_{n}\right)$ of $20 \mathrm{~nm}, 50 \mathrm{~nm}$ and $80 \mathrm{~nm}$; while $\mathrm{Al}, \mathrm{CuO}$ and $\mathrm{Al}_{2} \mathrm{O}_{3}$ nanoparticles have a single average diameter for each, and the average diameters are $20 \mathrm{~nm}, 40 \mathrm{~nm}$ and $20 \mathrm{~nm}$, respectively. The average diameter of nanoparticles is determined by the following steps: 1) observing the nanoparticles sample by TEM (transmission electron microscope); 2) obtaining the particle size distribution map (i.e., the proportion of the number of particles with different size range) based on TEM photographs of nanoparticles; 3) making the nanoparticle size corresponding to the peak value of the particle size distribution map to be the average diameter of nanoparticles. In the experiments for investigating the influence of nanoparticle type on the migration characteristics of nanoparticles, $\mathrm{Cu}$ $(20 \mathrm{~nm}), \mathrm{Al}(20 \mathrm{~nm})$ and $\mathrm{Al}_{2} \mathrm{O}_{3}(20 \mathrm{~nm})$ are used. In the experiments for investigating the influence of nanoparticle size on the migration characteristics of nanoparticles, $\mathrm{Cu}(20 \mathrm{~nm}), \mathrm{Cu}$ $(50 \mathrm{~nm})$ and $\mathrm{Cu}(80 \mathrm{~nm})$ are used. The properties of the used nanoparticles are given in Table 1, and the TEM (transmission electron microscope) photographs of the used nanoparticles are shown in Fig. 2.

Three types of refrigerants are used in the experiments including R113, R141b and n-pentane, belonging to CFC refrigerant, HCFC refrigerant and alkane refrigerant, respectively.

Table 1 - Properties of nanoparticles used in the experiments.

\begin{tabular}{|c|c|c|c|c|}
\hline Property & $\mathrm{Cu}$ & $\mathrm{Al}$ & $\mathrm{CuO}$ & $\mathrm{Al}_{2} \mathrm{O}_{3}$ \\
\hline Molecular mass $\left(\mathrm{g} \mathrm{mol}^{-1}\right)$ & 63.54 & 26.98 & 79.54 & 101.96 \\
\hline $\begin{array}{l}\text { Average particle diameter } \\
\text { (nm) }\end{array}$ & $20,50,80$ & 20 & 40 & 20 \\
\hline Density $\left(\mathrm{kg} \mathrm{m}^{-3}\right)$ & 8920 & 2688 & 6320 & 3890 \\
\hline $\begin{array}{l}\text { Thermal conductivity } \\
\left(\mathrm{W} \mathrm{m}^{-1} \mathrm{~K}^{-1}\right)\end{array}$ & 398 & 237 & 32.9 & 36 \\
\hline $\begin{array}{l}\text { Isobaric specific heat } \\
\left(\mathrm{J} \mathrm{kg}^{-1} \mathrm{~K}^{-1}\right)\end{array}$ & 385 & 905 & 550.5 & 779 \\
\hline
\end{tabular}




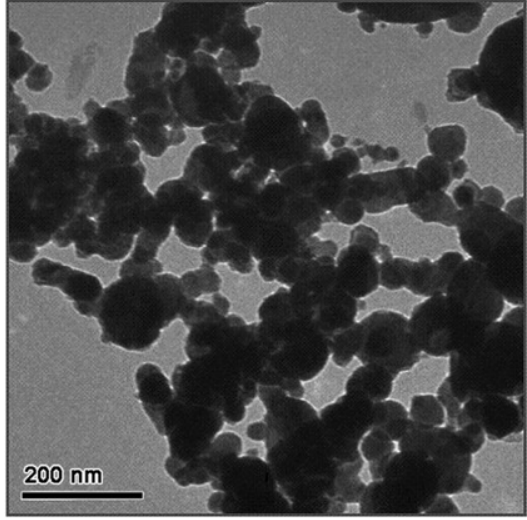

a $\mathrm{Cu}$ nanoparticles $\left(d_{\mathrm{n}}=20 \mathrm{~nm}\right)$

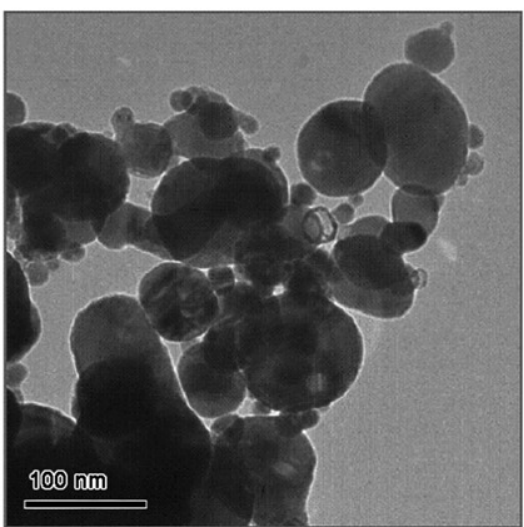

C Cu nanoparticles $\left(d_{\mathrm{n}}=80 \mathrm{~nm}\right)$

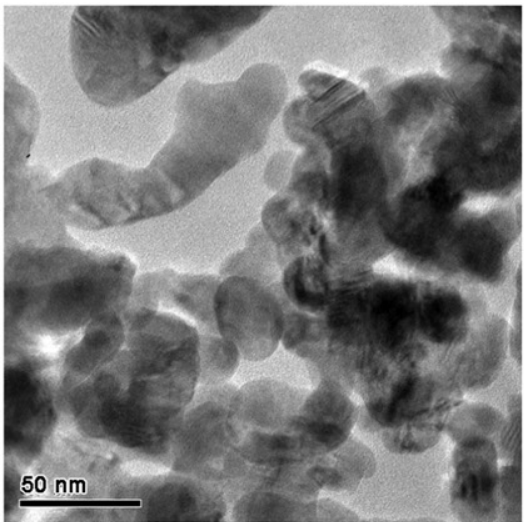

e $\mathrm{CuO}$ nanoparticles $\left(d_{\mathrm{n}}=40 \mathrm{~nm}\right)$

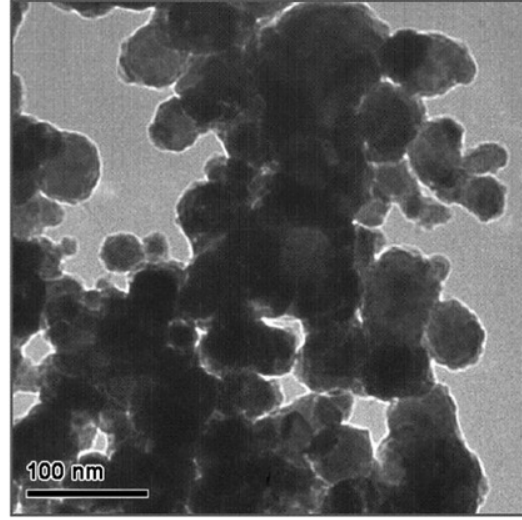

b Cu nanoparticles $\left(d_{\mathrm{n}}=50 \mathrm{~nm}\right)$

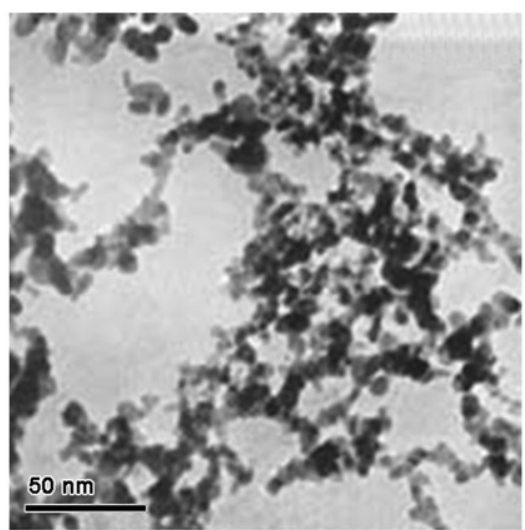

d Al nanoparticles $\left(d_{\mathrm{n}}=20 \mathrm{~nm}\right)$

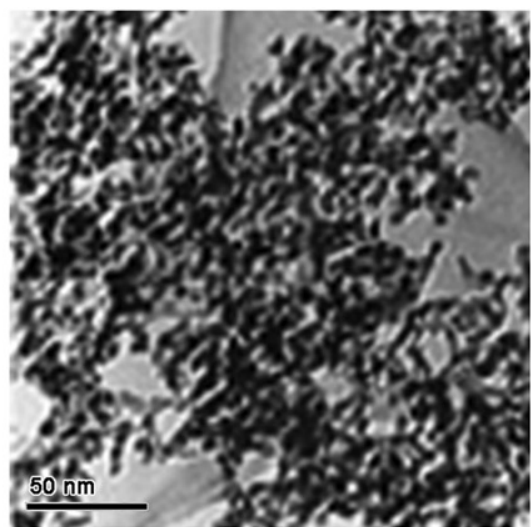

f $\mathrm{Al}_{2} \mathrm{O}_{3}$ nanoparticles $\left(d_{\mathrm{n}}=20 \mathrm{~nm}\right)$

Fig. 2 - TEM photographs of nanoparticles in the experiments.

Although these three refrigerants are not used any more in the refrigeration and air conditioning industry (e.g., R113 is a CFC and should be phased out), they are chosen in the present study based on the following two reasons. 1) If the host fluid is in liquid state at room temperature and atmospheric pressure, it is easy to disperse the nanoparticles into the host fluid evenly. However, most of widely used refrigerants, e.g. R410A, R134a and R22, are in vapor state at room temperature and atmospheric pressure, and it is difficult to prepare nanofluids with well-dispersed nanoparticles based on such refrigerants at room temperature and atmospheric pressure. R113, R141b and n-pentane are in liquid state at room temperature and atmospheric pressure (their boiling points are respectively $47.6^{\circ} \mathrm{C}$, $32.1^{\circ} \mathrm{C}$ and $36.1^{\circ} \mathrm{C}$ at $101.3 \mathrm{kPa}$ ). In order to prepare the refrigerant-based nanofluid with well-dispersed nanoparticles, these low-pressure refrigerants should be used as the host fluid (Ding et al., 2009). 2) The difference of the physical properties between R113, R141b or n-pentane and other widely used refrigerants (e.g. R410A, R134a) is quite smaller than that between refrigerants and non-refrigerant fluids (e.g. water), so the migration characteristics of nanoparticles in the refrigerantbased nanofluid based on R113, R141b or n-pentane may reflect 
those in other refrigerant-based nanofluids to a certain extent. The properties of the used refrigerants are given in Table 2.

For investigating the influence of mass fraction of lubricating oil on the migration characteristics of nanoparticles, the lubricating oil RB68EP is used in the experiments. RB68EP is an ester oil with a density of $0.964 \mathrm{~g} \mathrm{~cm}^{-3}$ at $15^{\circ} \mathrm{C}$ and kinematic viscosities of 66.79 and $8.23 \mathrm{~mm}^{2} \mathrm{~s}^{-1}$ at $40^{\circ} \mathrm{C}$ and $100^{\circ} \mathrm{C}$, respectively, as reported by the manufacturer. In order to avoid the sorption and agglutination phenomenon during nanofluid boiling heat transfer process (Liu and Liao, 2008), no surfactant is used in the present study.

\subsection{Test conditions}

Test conditions are tabulated in Table 3 , and are divided into six categories. The objectives of these six categories are investigating the influences of nanoparticle type, nanoparticle size, refrigerant type, mass fraction of lubricating oil, heat flux and initial liquid-level height on the migration of nanoparticles, respectively.

\section{Data reduction and uncertainty}

\subsection{Migration ratio of nanoparticles}

In order to quantitatively evaluate the migration degree of nanoparticles, the migration ratio of nanoparticles, $\zeta$, is defined by Eq. (1):

$\zeta=\Delta m_{\mathrm{n}} / m_{\mathrm{n} 0}$

where, $\Delta m_{\mathrm{n}}$ is the migrated mass of nanoparticles, and $m_{\mathrm{n}}$ is the original mass of nanoparticles.

\subsection{Initial nanoparticle concentration}

The initial nanoparticle concentration in the liquid-phase (liquid refrigerant or liquid refrigerant-oil mixture), $\varphi_{\mathrm{n}}$, can be calculated by Eq. (2):

\begin{tabular}{|c|c|c|c|}
\hline Property & R113 & R141b & n-pentane \\
\hline Chemical formula & Cl2FC-CClF2 & $\mathrm{CH} 3 \mathrm{CCl} 2 \mathrm{~F}$ & C5H12 \\
\hline Molecular mass $\left(\mathrm{g} \mathrm{mol}^{-1}\right)$ & 187.37 & 116.95 & 72.15 \\
\hline Normal boiling point $\left({ }^{\circ} \mathrm{C}\right)$ & 47.6 & 32.05 & 36.1 \\
\hline Critical temperature $\left({ }^{\circ} \mathrm{C}\right)$ & 214.1 & 204.5 & 196.4 \\
\hline Critical pressure (MPa) & 3.39 & 4.25 & 3.37 \\
\hline $\begin{array}{l}\text { Liquid-phase } \\
\quad \text { density }\left(\mathrm{kg} \mathrm{m}^{-3}\right)(1 \mathrm{~atm})\end{array}$ & 1508 & 1220 & 606 \\
\hline $\begin{array}{l}\text { Vapor-phase } \\
\text { density }\left(\mathrm{kg} \mathrm{m}^{-3}\right)(1 \mathrm{~atm})\end{array}$ & 7.4 & 4.8 & 3.2 \\
\hline $\begin{array}{l}\text { Liquid-phase dynamic } \\
\text { viscosity (Pa s) (1 atm) }\end{array}$ & $5 \times 10^{-4}$ & $3.78 \times 10^{-4}$ & $1.91 \times 10^{-4}$ \\
\hline $\begin{array}{l}\text { Liquid-phase isobaric } \\
\text { specific heat } \\
\left(\mathrm{J} \mathrm{kg}^{-1} \mathrm{~K}^{-1}\right)(1 \mathrm{~atm})\end{array}$ & 940 & 1165 & 2441 \\
\hline $\begin{array}{l}\text { Surface tension } \\
\qquad\left(\mathrm{N} \mathrm{m}^{-1}\right)(1 \mathrm{~atm})\end{array}$ & 0.0147 & 0.0173 & 0.0138 \\
\hline
\end{tabular}

$$
\varphi_{\mathrm{n}}=\frac{m_{\mathrm{no}} / \rho_{\mathrm{n}}}{m_{\mathrm{n} 0} / \rho_{\mathrm{n}}+m_{\mathrm{r} 0} / \rho_{\mathrm{r}, \mathrm{L}}+m_{\mathrm{o}} / \rho_{\mathrm{o}}}
$$

where, $m_{\mathrm{ro}}$ and $m_{\mathrm{o}}$ are the original mass of refrigerant and the mass of oil, respectively; $\rho_{\mathrm{n}}, \rho_{\mathrm{r}, \mathrm{L}}$ and $\rho_{\mathrm{o}}$ are the density of nanoparticle, liquid-phase refrigerant and oil, respectively.

\subsection{Mass fraction of lubricating oil}

The mass fraction of lubricating oil in the liquid refrigerant-oil mixture, $x_{0}$, is calculated by Eq. (3):

$x_{\mathrm{o}}=\frac{m_{\mathrm{o}}}{m_{\mathrm{r} 0}+m_{\mathrm{o}}}$

\subsection{Uncertainties}

The uncertainty of migration ratio of nanoparticles, $\delta \zeta$, is calculated as:

$\delta \zeta=\sqrt{\left(\frac{\partial \zeta}{\partial \Delta m_{\mathrm{n}}}\right)^{2} \delta \Delta m_{\mathrm{n}}^{2}+\left(\frac{\partial \zeta}{\partial m_{\mathrm{n} 0}}\right)^{2} \delta m_{\mathrm{n} 0}^{2}}$

By substituting Eq. (1) to Eq. (4), the relative uncertainty of migration ratio of nanoparticles is calculated as:

$\frac{\delta \zeta}{\zeta}=\sqrt{\left(\frac{1}{\Delta m_{\mathrm{n}}}\right)^{2} \delta \Delta m_{\mathrm{n}}^{2}+\left(\frac{1}{m_{\mathrm{n} 0}}\right)^{2} \delta m_{\mathrm{n} 0}^{2}}$

Determined by the accuracy of the digital electronic balance, the maximum uncertainties of the measured migrated mass of nanoparticles $\left(\delta \Delta m_{\mathrm{n}}\right)$ and original mass of nanoparticles $\left(\delta \mathrm{m}_{0}\right)$ are $0.2 \mathrm{mg}$ and $0.1 \mathrm{mg}$, respectively. The maximum relative uncertainty of migration ratio of nanoparticles is obtained at the condition of the smallest migrated mass of nanoparticles and the original mass of nanoparticles, and calculated to be $2.7 \%$.

Tests under several conditions were repeated for three times. The differences among the three testing results under each condition are less than $3 \%$, which shows that the experimental results are reproducible.

\section{Results and discussion}

\subsection{Influence of nanoparticle type on the migration of nanoparticles}

Fig. 3 shows the migration ratio ( $\zeta$ ) of nanoparticles changed with the initial nanoparticle concentration $\left(\varphi_{n}\right)$ for different nanoparticle type. The refrigerant is R113, the mass fraction of lubricating oil $\left(x_{\circ}\right)$ is $0 \mathrm{wt} \%$, the heat flux $(q)$ is $50 \mathrm{~kW} \mathrm{~m}^{-2}$, and the initial liquid-level height $(L)$ is $2.0 \mathrm{~cm}$. The value of $\zeta$ under these test conditions is in the range of $15.4-30.7 \%$. For fixed nanoparticle type, $\zeta$ decreases with the increase of $\varphi_{\mathrm{n}}$. For example, $\zeta$ for $\mathrm{Al}(20 \mathrm{~nm})$ decreases $27.3 \%$ with the increase of $\varphi_{\mathrm{n}}$ from $0.2 \mathrm{vol} \%$ to $1.37 \mathrm{vol} \%$. The tendency of $\zeta$ changed with $\varphi_{\mathrm{n}}$ is same to that for CuO presented by Ding et al. (2009).

From Fig. 3, it can be seen that the migration ratio $(\zeta)$ of nanoparticles is in the order of $\mathrm{Al}(20 \mathrm{~nm})>\mathrm{Al}_{2} \mathrm{O}_{3}(20 \mathrm{~nm})>\mathrm{Cu}$ $(20 \mathrm{~nm})$, which is opposite to the order of the density values for $\mathrm{Al}\left(2688 \mathrm{~kg} \mathrm{~m}^{-3}\right), \mathrm{Al}_{2} \mathrm{O}_{3}\left(3890 \mathrm{~kg} \mathrm{~m}^{-3}\right)$ and $\mathrm{Cu}\left(8920 \mathrm{~kg} \mathrm{~m}^{-3}\right)$. 
Table 3 - Test conditions.

\begin{tabular}{|c|c|c|c|c|c|c|}
\hline $\begin{array}{l}\text { Objective of } \\
\text { investigation }\end{array}$ & $\begin{array}{l}\text { Nanopaticle } \\
\text { type and size }\end{array}$ & $\begin{array}{l}\text { Refrigerant } \\
\text { type }\end{array}$ & $\begin{array}{l}\text { Mass fraction } \\
\text { of lubricating } \\
\text { oil } x_{o}(w t \%)\end{array}$ & $\begin{array}{l}\text { Heat flux } \\
q\left(\mathrm{~kW} \mathrm{~m}^{-2}\right)\end{array}$ & $\begin{array}{c}\text { Initial } \\
\text { liquid-level } \\
\text { height L }(\mathrm{cm})\end{array}$ & $\begin{array}{c}\text { Initial nanoparticle } \\
\text { concentration } \varphi_{\mathrm{n}}(\mathrm{vol} \%)\end{array}$ \\
\hline $\begin{array}{l}\text { Influence of nanoparticle } \\
\text { type on migration }\end{array}$ & $\begin{array}{l}\mathrm{Cu}(20 \mathrm{~nm}), \\
\mathrm{Al}(20 \mathrm{~nm}), \\
\mathrm{Al}_{2} \mathrm{O}_{3}(20 \mathrm{~nm})\end{array}$ & R113 & 0 & 50 & 2.0 & $\begin{array}{l}0.2,0.4,0.59,0.79 \\
0.98,1.18,1.37\end{array}$ \\
\hline $\begin{array}{l}\text { Influence of nanoparticle } \\
\text { size on the migration }\end{array}$ & $\begin{array}{l}\mathrm{Cu}(20 \mathrm{~nm}), \\
\mathrm{Cu}(50 \mathrm{~nm}), \\
\mathrm{Cu}(80 \mathrm{~nm})\end{array}$ & R113 & 0 & 50 & 2.0 & $\begin{array}{l}0.2,0.4,0.59,0.79 \\
0.98,1.18,1.37\end{array}$ \\
\hline $\begin{array}{l}\text { Influence of refrigerant } \\
\text { type on migration }\end{array}$ & $\mathrm{CuO}(40 \mathrm{~nm})$ & $\begin{array}{l}\text { R113, R141b, } \\
\text { n-pentane }\end{array}$ & 0 & 50 & 2.0 & $\begin{array}{l}0.2,0.4,0.59,0.79 \\
0.98,1.18,1.37\end{array}$ \\
\hline $\begin{array}{l}\text { Influence of mass fraction } \\
\text { of lubricating oil } \\
\text { on migration }\end{array}$ & $\mathrm{CuO}(40 \mathrm{~nm})$ & R113 & $0,1,5,10$ & 50 & 2.0 & $\begin{array}{l}0.2,0.4,0.59,0.79 \\
0.98,1.18,1.37\end{array}$ \\
\hline $\begin{array}{l}\text { Influence of heat flux } \\
\text { on migration }\end{array}$ & $\mathrm{CuO}(40 \mathrm{~nm})$ & R113 & 0 & $\begin{array}{l}10,20 \\
50,100\end{array}$ & 2.0 & $\begin{array}{l}0.2,0.4,0.59,0.79 \\
0.98,1.18,1.37\end{array}$ \\
\hline $\begin{array}{l}\text { Influence of initial } \\
\text { liquid-level height } \\
\text { on migration }\end{array}$ & $\mathrm{CuO}(40 \mathrm{~nm})$ & R113 & 0 & 50 & $1.3,2.02 .7,3.4$ & $\begin{array}{l}0.2,0.4,0.59,0.79 \\
0.98,1.18,1.37\end{array}$ \\
\hline
\end{tabular}

Under the present experimental conditions, the value of $\zeta$ for Al $(20 \mathrm{~nm})$ is maximally $19.6 \%$ larger than that for $\mathrm{Al}_{2} \mathrm{O}_{3}$ $(20 \mathrm{~nm})$, and is maximally $67.9 \%$ larger than that for $\mathrm{Cu}$ $(20 \mathrm{~nm})$. The possible reason for this phenomenon is as follows. The Brownian movement velocity of nanoparticles increases with the decrease of nanoparticle density (Prasher et al., 2006), causing a larger number of nanoparticles approach and be captured by the bubbles, which leads to the $\zeta$ increasing with the decrease of the nanoparticle density.

\subsection{Influence of nanoparticle size on the migration of nanoparticles}

Fig. 4 shows the migration ratio ( $\zeta)$ of nanoparticles changed with the initial nanoparticle concentration $\left(\varphi_{\mathrm{n}}\right)$ for different

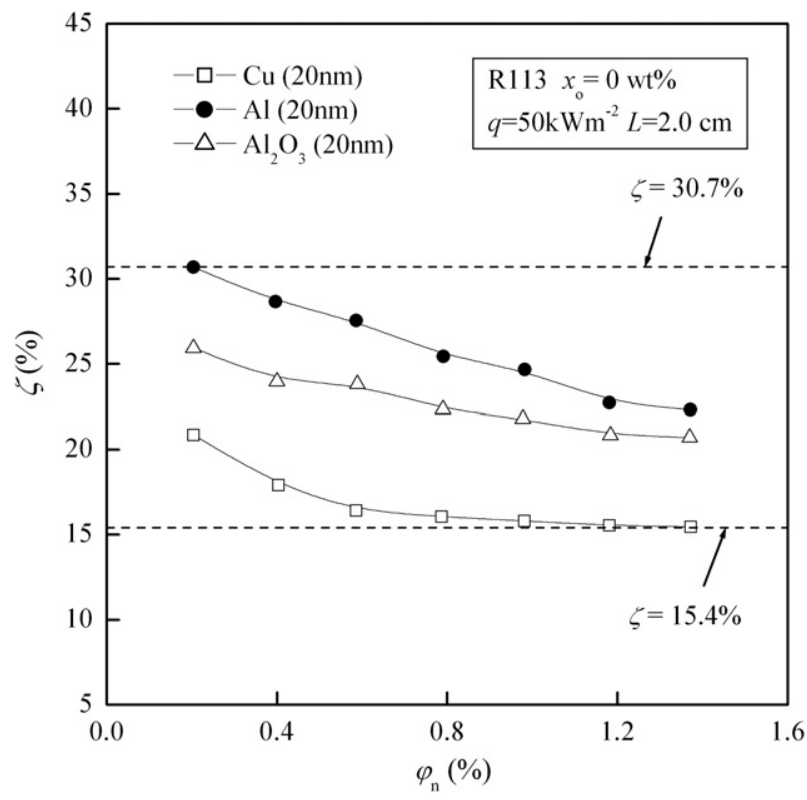

Fig. 3 - Influence of nanoparticle type on the migration ratio of nanoparticles. nanoparticle size. The refrigerant is R113, the mass fraction of lubricating oil $\left(x_{0}\right)$ is $0 \mathrm{wt} \%$, the heat flux $(q)$ is $50 \mathrm{~kW} \mathrm{~m}^{-2}$, and the initial liquid-level height $(L)$ is $2.0 \mathrm{~cm}$. The value of $\zeta$ under these test conditions is in the range of $2.8-20.9 \%$. For fixed nanoparticle size, $\zeta$ decreases with the increase of $\varphi_{\mathrm{n}}$. For example, $\zeta$ for $\mathrm{Cu}(50 \mathrm{~nm})$ decreases $52.2 \%$ with the increase of $\varphi_{\mathrm{n}}$ from 0.2 vol\% to 1.37 vol\%.

From Fig. 4, it can be seen that the migration ratio ( $)$ of nanoparticles increases with the decrease of nanoparticle size. Under the present experimental conditions, the value of $\zeta$ for $\mathrm{Cu}(20 \mathrm{~nm})$ is maximally $315.6 \%$ larger than that for $\mathrm{Cu}$ $(50 \mathrm{~nm})$, and is maximally $448 \%$ larger than that for $\mathrm{Cu}$ $(80 \mathrm{~nm})$. The difference of $\zeta$ between $\mathrm{Cu}(20 \mathrm{~nm})$ and $\mathrm{Cu}$ $(50 \mathrm{~nm})$ is much larger than that between $\mathrm{Cu}(50 \mathrm{~nm})$ and $\mathrm{Cu}$ $(80 \mathrm{~nm})$, which shows that the increase of $\zeta$ with the decrease

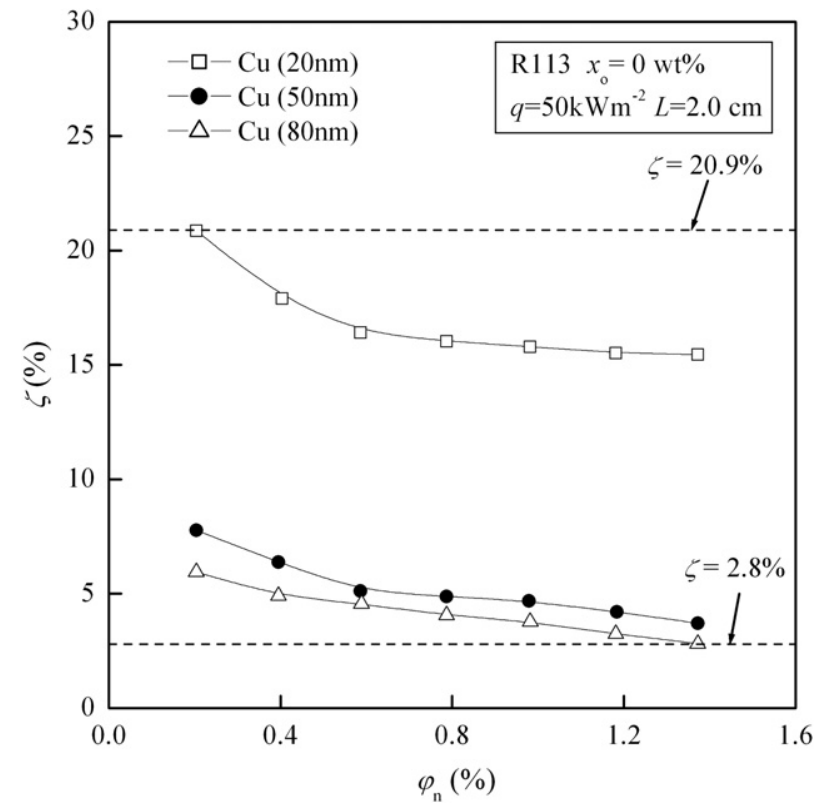

Fig. 4 - Influence of nanoparticle size on the migration ratio of nanoparticles. 
of the nanoparticle size is non-linear. The possible reasons for this phenomenon are as follows. 1) According to the flotation

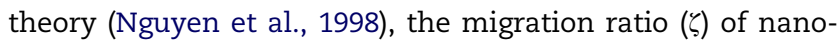
particles is proportional to the collision efficiency between nanoparticles and bubbles caused by the Brownian diffusion, as well as the Brownian movement velocity of nanoparticles. 2) The collision efficiency is reverse to the nanoparticle size (Edzwald et al., 1990) and the Brownian movement velocity of nanoparticles is reverse to $3 / 2$ power of the nanoparticle size (Prasher et al., 2006), which leads to the $\zeta$ increasing nonlinearly with the decrease of the nanoparticle size.

\subsection{Influence of refrigerant type on the migration of nanoparticles}

Fig. 5 shows the migration ratio ( $\zeta)$ of nanoparticles changed with the initial nanoparticle concentration $\left(\varphi_{\mathrm{n}}\right)$ for different refrigerant type. The nanoparticle is $\mathrm{CuO}(40 \mathrm{~nm})$, the mass fraction of lubricating oil $\left(x_{0}\right)$ is $0 \mathrm{wt} \%$, the heat flux $(q)$ is $50 \mathrm{~kW} \mathrm{~m}^{-2}$, and the initial liquid-level height $(L)$ is $2.0 \mathrm{~cm}$. The value of $\zeta$ under these test conditions is in the range of $3.7-12.5 \%$. For fixed refrigerant type, $\zeta$ decreases with the increase of $\varphi_{\mathrm{n}}$. For example, $\zeta$ for R141b decreases $51.5 \%$ with the increase of $\varphi_{\mathrm{n}}$ from $0.2 \mathrm{vol} \%$ to $1.37 \mathrm{vol} \%$.

From Fig. 5, it can be seen that the migration ratio ( $\zeta)$ of nanoparticles is in the order of $\mathrm{R} 141 \mathrm{~b}>\mathrm{R} 113>\mathrm{n}$-pentane. Under the present experimental conditions, the value of $\zeta$ in R141b-based nanofluid is maximally $23.4 \%$ larger than that in R113-based nanofluid, and is maximally $88.6 \%$ larger than that in $\mathrm{n}$-pentane-based nanofluid. The influence of refrigerant type on the migration ratio of nanoparticles is determined by the conjunct role of the following two aspects.

1) The influence of dynamic viscosity of refrigerant on the migration ratio of nanoparticles.

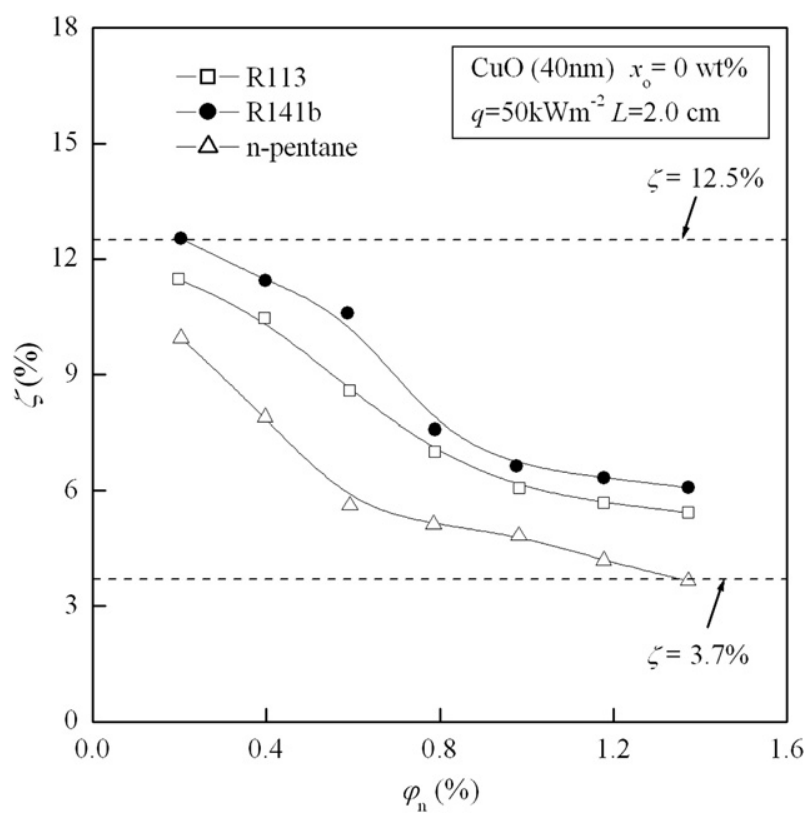

Fig. 5 - Influence of refrigerant type on the migration ratio of nanoparticles.
With the increase of dynamic viscosity of refrigerant, the collision efficiency of nanoparticles decreases, and so the migration ratio of nanoparticles decreases.

2) The influence of liquid-phase density of refrigerant on the migration ratio of nanoparticles.

With the increase of liquid-phase density of refrigerant, the amount of generated bubbles at fixed initial liquid-level height increases, and so the migration ratio of nanoparticles increases.

The dynamic viscosity values and the liquid-phase density values for three refrigerants used in the experiments are both in the order of R113 > R141b > n-pentane. As the influences of dynamic viscosity and liquid-phase density of refrigerant on the migration ratio of nanoparticles are inverse, the conjunct role causes the migration ratio of nanoparticles in the order of R141b > R113 > n-pentane.

\subsection{Influence of mass fraction of lubricating oil on the migration of nanoparticles}

Fig. 6 shows the migration ratio ( $\zeta)$ of nanoparticles changed with the initial nanoparticle concentration $\left(\varphi_{n}\right)$ for different mass fraction of lubricating oil $\left(x_{0}\right)$. The nanoparticle is $\mathrm{CuO}$ $(40 \mathrm{~nm})$, the refrigerant is R113, the heat flux $(q)$ is $50 \mathrm{~kW} \mathrm{~m}^{-2}$, and the initial liquid-level height $(L)$ is $2.0 \mathrm{~cm}$. The value of $\zeta$ under these test conditions is in the range of $0.8-11.5 \%$. For fixed $x_{0}, \zeta$ decreases with the increase of $\varphi_{\mathrm{n}}$. For example, at the condition of $x_{0}=5 \mathrm{wt} \%, \zeta$ decreases $38.4 \%$ with the increase of $\varphi_{\mathrm{n}}$ from 0.2 vol\% to 1.37 vol\%.

From Fig. 6 , it can be seen that the migration ratio ( $\zeta)$ of nanoparticles decreases maximally $79.1 \%$ with the increase of mass fraction of lubricating oil $\left(x_{\circ}\right)$ from $1 \mathrm{wt} \%$ to $10 \mathrm{wt} \%$. The possible reasons for this phenomenon are as follows. 1) The dynamic viscosity and surface tension of lubricating oil RB68EP are larger than those of pure refrigerant, causing the dynamic viscosity and surface tension of liquid-phase refrigerant-oil mixture increase with the increase of $x_{\circ}$ (Jensen and Jackman, 1984; Kedzierski and Kaul, 1993; Mermond et al., 1999). 2) The increase of dynamic viscosity of the liquidphase refrigerant-oil mixture causes the decrease of collision efficiency caused by Brownian diffusion, which leads to $\zeta$ decreasing with the increase of $x_{0}$. 3) The increase of surface tension of the liquid-phase refrigerant-oil mixture causes the increase of the bubble departure diameter during the pool boiling process. The nanoparticles-bubble collision efficiency decreases with the increase of bubble diameter (Edzwald et al., 1990), causing the decrease of the amount of nanoparticles captured by bubbles, which leads to $\zeta$ decreasing with the increase of $x_{0}$.

\subsection{Influence of heat flux on the migration of nanoparticles}

Fig. 7 shows the migration ratio ( $\zeta)$ of nanoparticles changed with the initial nanoparticle concentration $\left(\varphi_{n}\right)$ for different heat flux (q) in the present study. The nanoparticle is $\mathrm{CuO}$ $(40 \mathrm{~nm})$, the refrigerant is R113, the mass fraction of lubricating oil $\left(x_{o}\right)$ is $0 \mathrm{wt} \%$, and the initial liquid-level height $(L)$ is $2.0 \mathrm{~cm}$. 


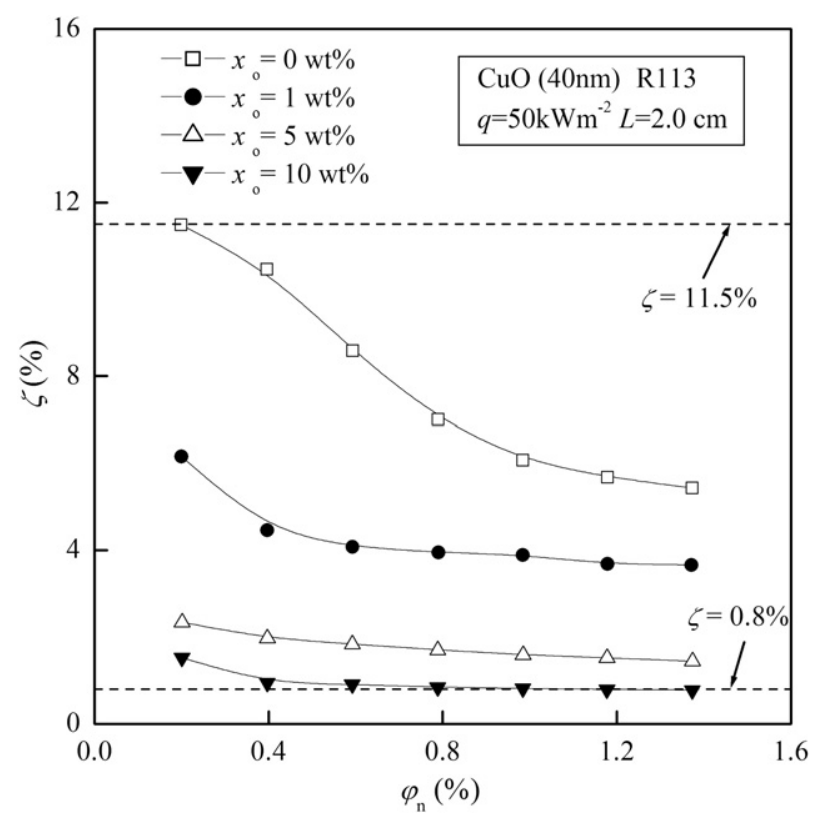

Fig. 6 - Influence of mass fraction of lubricating oil on the migration ratio of nanoparticles.

The value of $\zeta$ under these test conditions is in the range of 5.3-14.1\%. For fixed $q, \zeta$ decreases with the increase of $\varphi_{\mathrm{n}}$. For example, at the condition of $q=10 \mathrm{~kW} \mathrm{~m}^{-2}$, $\zeta$ decreases $54.5 \%$ with the increase of $\varphi_{\mathrm{n}}$ from 0.2 vol\% to 1.37 vol\%.

From Fig. 7, it can be seen that the migration ratio ( $\zeta)$ of nanoparticles in the present study decreases maximally $36.2 \%$ with the increase of heat flux (q) from $10 \mathrm{~kW} \mathrm{~m}^{-2}$ to $100 \mathrm{~kW} \mathrm{~m}^{-2}$. The possible reasons are as follows. 1) The increase of heat flux causes the increase of the velocity of departure bubble (Malenkov, 1971), thus the velocity of rising bubble increases. 2) The increase of velocity of rising bubble

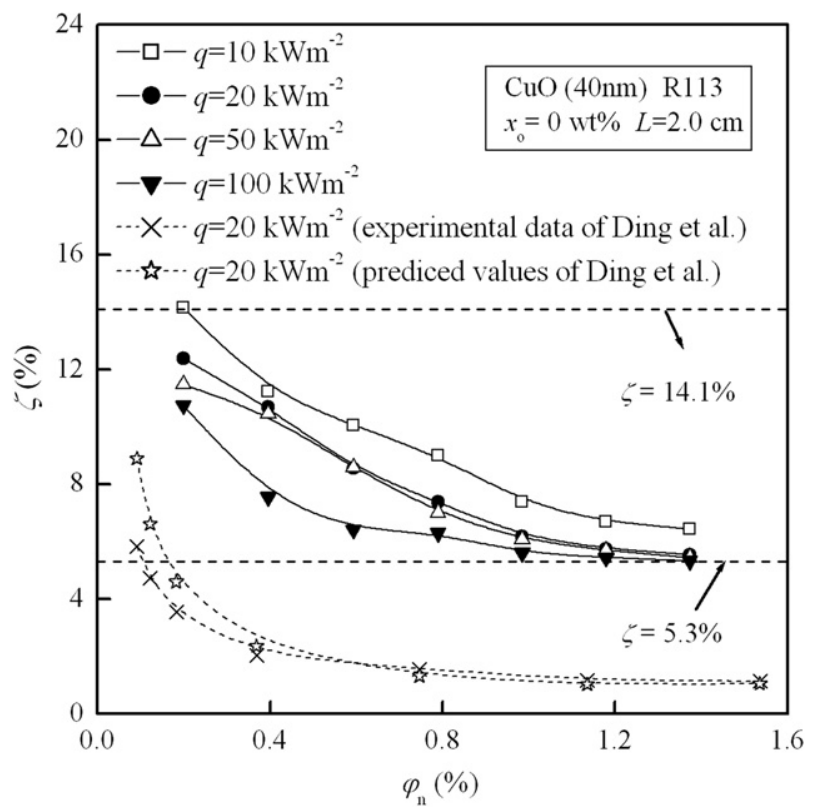

Fig. 7 - Influence of heat flux on the migration ratio of nanoparticles. results in the decrease of nanoparticles-bubble collision efficiency caused by Brownian diffusion, which leads to the decrease of $\zeta$. 3) The increase of velocity of rising bubble results in the decrease of the bubble rising time in the liquid-phase, causing the decrease of the amount of nanoparticles captured by bubbles, which leads to the decrease of $\zeta$. It can also be seen that the migration ratio $(\zeta)$ of nanoparticles at the heat flux of $20 \mathrm{~kW} \mathrm{~m}^{-2}$ is close to those at the heat flux of $50 \mathrm{~kW} \mathrm{~m}^{-2}$. The possible reason for this phenomenon is as follows. With the increase of heat flux from $20 \mathrm{~kW} \mathrm{~m}^{-2}$ to $50 \mathrm{~kW} \mathrm{~m}^{-2}$, the rising bubble velocity increases slightly. The small increase of bubble velocity leads to the small decrease of nanoparticles-bubble collision efficiency as well as bubble rising time, and so the migration ratio of nanoparticles decreases slightly.

Fig. 7 also shows the experimental data and predicted values of migration ratio ( $\zeta$ ) of nanoparticles presented by Ding et al. (2009). It can be seen from Fig. 7 that the values of $\zeta$ presented by Ding et al. are different from those in the present study. The possible reason for this phenomenon is as follows. The radiation heating was used in the study of Ding et al., causing the generation of bubbles on the side wall of the boiling vessel. In the present study, in order to reflect the actual pool boiling process, the electric heating is used, causing the generation of bubbles on the bottom of the boiling vessel. The differences of bubbles rising process as well as the interaction between nanoparticles and bubbles result in the values of $\zeta$ presented by Ding et al. are different from those in the present study.

\subsection{Influence of initial liquid-level height on the migration of nanoparticles}

Fig. 8 shows the migration ratio ( $\zeta)$ of nanoparticles changed with the initial nanoparticle concentration $\left(\varphi_{\mathrm{n}}\right)$ for different initial liquid-level height $(\mathrm{L})$. The nanoparticle is $\mathrm{CuO}(40 \mathrm{~nm})$, the refrigerant is R113, the mass fraction of lubricating oil $\left(x_{\circ}\right)$

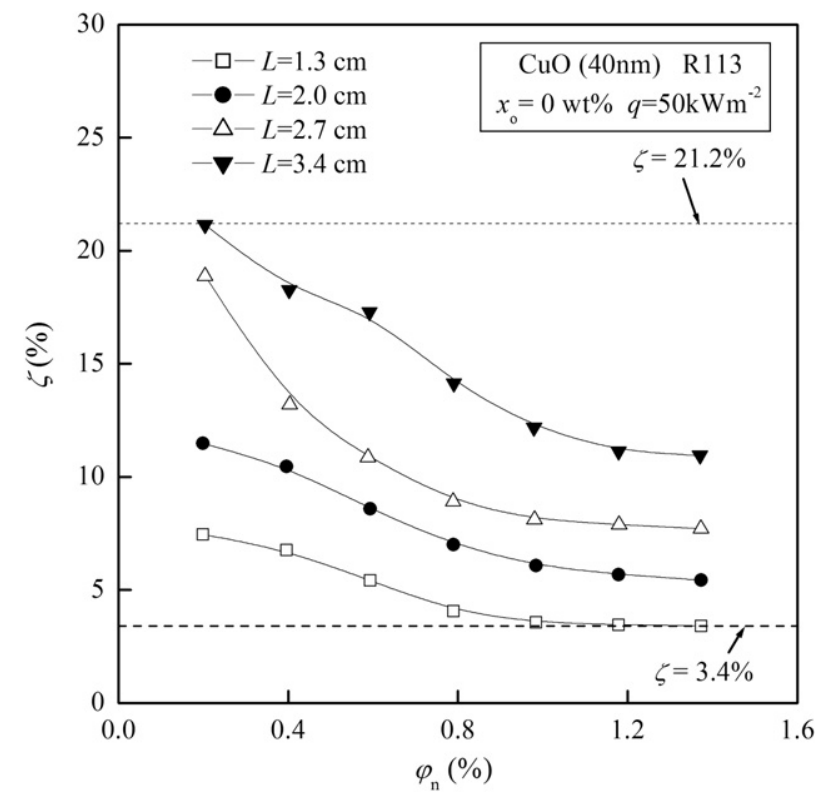

Fig. 8 - Influence of initial liquid-level height on the migration ratio of nanoparticles. 
is $0 \mathrm{wt} \%$, and the heat flux (q) is $50 \mathrm{~kW} \mathrm{~m}^{-2}$. The value of $\zeta$ under these test conditions is in the range of $3.4-21.2 \%$. For fixed $L, \zeta$ decreases with the increase of $\varphi_{n}$. For example, at the condition of $L=2.7 \mathrm{~cm}$, $\zeta$ decreases $59.2 \%$ with the increase of $\varphi_{\mathrm{n}}$ from $0.2 \mathrm{vol} \%$ to $1.37 \mathrm{vol} \%$.

From Fig. 8, it can be seen that the migration ratio ( $)$ of nanoparticles increases maximally $247.5 \%$ with the increase of initial liquid-level height $(L)$ from $1.3 \mathrm{~cm}$ to $3.4 \mathrm{~cm}$. The possible reasons are as follows. 1) The increase of initial liquid-level height causes the increase of the bubble rising time in the liquid-phase, thus the amount of nanoparticles captured by bubbles increases, which leads to $\zeta$ increasing with the increase of initial liquid-level height. 2) The increase of initial liquid-level height causes the increase of nanoparticles escape probability from the liquid-vapor interface, which leads to $\zeta$ increasing with the increase of initial liquid-level height.

\section{Comparison between experimental results and existing model predictions}

Ding et al. (2009) model is the only existing model for predicting the migration characteristics of nanoparticles during the refrigerant-based nanofluid pool boiling process.

In Ding et al. model, the total migrated mass of nanoparticles $\left(\Delta m_{n}\right)$ includes the migrated mass of nanoparticles by individual escaping $\left(m_{\mathrm{p}, \mathrm{i}}\right)$ and the migrated mass of nanoparticles by bubble adhesion $\left(m_{\mathrm{p}, \mathrm{b}, \mathrm{max}}\right) \cdot m_{\mathrm{p}, \mathrm{i}}$ is obtained by the energy conservation principle (i.e., the surface work is equal to the difference between the kinetic energy of single nanoparticle before escaping and that after escaping). $m_{\mathrm{p}, \mathrm{b}, \max }$ is also obtained by the energy conservation principle (i.e., the surface work is equal to the kinetic energy loss of bubbles and nanoparticles). The main equations in Ding et al. model are listed as follows.

$$
\begin{aligned}
& \Delta m_{\mathrm{n}}=m_{\mathrm{p}, \mathrm{i}}+m_{\mathrm{p}, \mathrm{b}, \max } \\
& m_{\mathrm{p}, \mathrm{i}}=m_{\mathrm{n} 0} \cdot R\left(u>u_{0, \min }\right) \\
& u_{0, \min }=\sqrt{\frac{12 \gamma}{\rho_{\mathrm{n}} d}} \\
& R\left(u>u_{0, \min }\right)=\int_{u_{0, \min }}^{\infty} 4 \pi\left(\frac{m}{2 \pi k_{\mathrm{B}} \mathrm{T}}\right)^{3 / 2} e^{-\frac{m}{2 k_{\mathrm{B}} \mathrm{T}} u^{2}} u^{2} \mathrm{~d} u \\
& m_{\mathrm{p}, \mathrm{b}, \max }=\frac{\bar{u}^{2}}{\frac{12 \gamma}{\rho_{\mathrm{n}} d}-\bar{u}^{2}} m_{\mathrm{b}}
\end{aligned}
$$

In Eqs. (6)-(10), $u_{0, \min }$ is the minimum velocity of single nanoparticle before escaping from the liquid surface (defined as minimum escaping velocity); $u$ is the velocity of single nanoparticle; $R\left(u>u_{0, \min }\right)$ is the ratio of number of nanoparticles with velocity larger than $u_{0, \min }$ to the total number of nanoparticles; $\gamma$ is the surface tension of liquid; $d$ is the diameter of single nanoparticle; the Boltzmann constant $k_{\mathrm{B}}=1.381 \times 10^{-23} \mathrm{JK}^{-1} ; \mathrm{T}$ is the temperature; $\bar{u}$ is the average velocity of bubbles; $m_{\mathrm{b}}$ is the mass of bubbles, which is equal to the original mass of refrigerant $m_{\mathrm{ro}}$ when all the refrigerant is gasified.
The predictability of Ding et al. model has been verified by the experimental data presented by Ding et al. (2009), covering the $\mathrm{CuO}(40 \mathrm{~nm})$ nanoparticle, the refrigerant R113, the heat flux of $20 \mathrm{~kW} \mathrm{~m}^{-2}$, and the initial concentration of $\mathrm{CuO}$ nanoparticles from 0.09 vol\% to $1.54 \mathrm{vol} \%$. The verification results showed that the average deviations of Ding et al. model predictions from the experimental data presented by Ding et al. (2009) are in the range of $7.7-38.4 \%$. Due to the experimental data presented by Ding et al. (2009) concerned only one type of nanoparticle and one type refrigerant at a single heat flux, the predictabilities of Ding et al. model to other experimental conditions are uncertain and should be investigated.

The present experimental conditions are more complicated than the experimental data presented by Ding et al. (2009), and cover different nanoparticle type (Cu, $\mathrm{Al}$ and $\mathrm{Al}_{2} \mathrm{O}_{3}$ ) nanoparticle size $(20-80 \mathrm{~nm})$, refrigerant type (R113, $\mathrm{R} 141 \mathrm{~b}$ and $\mathrm{n}$-pentane), mass fraction of lubricating oil (0-10 wt\%), heat flux $\left(10-100 \mathrm{~kW} \mathrm{~m}^{-2}\right)$, initial liquid-level height $(1.3-3.4 \mathrm{~cm})$ and initial nanoparticle concentration (0.2-1.37 vol\%). Therefore, the predictabilities of Ding et al. model to the present experimental data are uncertain, and will be checked in this paper.

Fig. 9 shows the comparison between the present experimental data of migration ratio of nanopartilces and the predicted values of Ding et al. (2009) model. From Fig. 9, it can be seen that the predicted values agree with $82 \%$ of the present experimental data within $\pm 90 \%$, and the mean deviation is $65.3 \%$. Such large deviation is due to that Ding et al. model does not consider the influences of refrigerant-based nanofluid composition (including nanoparticle type, nanoparticle size, refrigerant type and mass fraction of lubricating oil) and heating condition (including heat flux and initial liquid-level height) on the bubble dynamic characteristics or nanoparticle-bubble interaction. Therefore, a new model will be developed in Part II of the present study, reflecting the influences of refrigerant-based nanofluid composition and heating

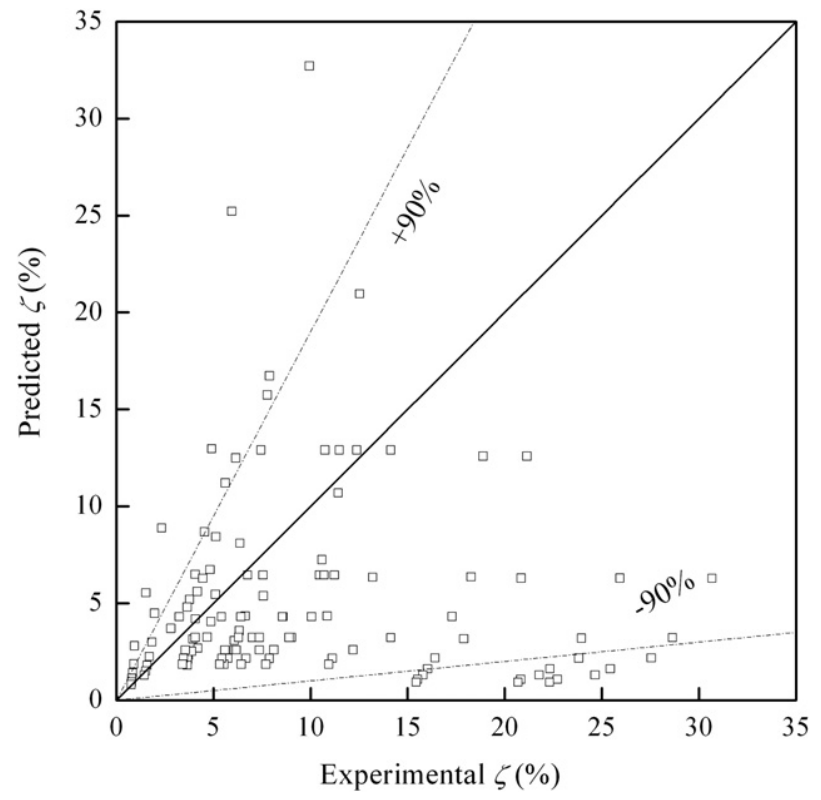

Fig. 9 - Comparison between the experimental data and the predicted values of Ding et al. (2009) model. 
condition on the migration characteristics of nanoparticles. The comparison between experimental results and the new model will be introduced in Part II of the present study.

\section{Conclusions}

Influences of refrigerant-based nanofluid composition and heating condition on the migration of nanoparticles during the pool boiling process of refrigerant-based nanofluid are investigated experimentally, and some conclusions are obtained.

(1) The order of migration ratio of nanoparticles is opposite to the order of the density values of nanoparticles. Under the present experimental conditions, the migration ratio for $\mathrm{Al}$ $(20 \mathrm{~nm})$ is maximally $19.6 \%$ larger than that for $\mathrm{Al}_{2} \mathrm{O}_{3}(20 \mathrm{~nm})$, and is maximally $67.9 \%$ larger than that for $\mathrm{Cu}(20 \mathrm{~nm})$.

(2) The migration ratio of nanoparticles increases with the decrease of nanoparticle size. Under the present experimental conditions, the value of $\zeta$ for $\mathrm{Cu}(20 \mathrm{~nm})$ is maximally $315.6 \%$ larger than that for $\mathrm{Cu}(50 \mathrm{~nm})$, and is maximally $448 \%$ larger than that for $\mathrm{Cu}(80 \mathrm{~nm})$.

(3) The migration ratio of nanoparticles increases with the decrease of dynamic viscosity of refrigerant or the increase of liquid-phase density of refrigerant.

(4) The migration ratio of nanoparticles decreases maximally $79.1 \%$ with the increase of mass fraction of lubricating oil from 1 to $10 \mathrm{wt} \%$, decreases maximally $36.2 \%$ with the increase of heat flux from 10 to $100 \mathrm{~kW} \mathrm{~m}^{-2}$, and increases maximally $247.5 \%$ with the increase of initial liquid-level height from 1.3 to $3.4 \mathrm{~cm}$.

(5) Ding et al. model cannot predict the present experimental data accurately because it does not consider the influences of refrigerant-based nanofluid composition and heating condition on the bubble dynamic characteristics or nanoparticle-bubble interaction. Development of a new model reflecting the influences of refrigerant-based nanofluid composition and heating condition on the migration characteristics of nanoparticles is needed.

\section{Acknowledgments}

The authors gratefully acknowledge the support from the National Natural Science Foundation of China (Grant No. 50976065) and the Postdoctoral Sustentation Fund of Shanghai (Grant No. 09R21413500).

\section{R E F E R E N C E S}

Bi, S.S., Shi, L., Zhang, L.L., 2008. Application of nanoparticles in domestic refrigerators. Appl. Therm. Eng. 28, 1834-1843.
Ding, G.L., Peng, H., Jiang, W.T., Gao, Y.F., 2009. The migration characteristics of nanoparticles in the pool boiling process of nanorefrigerant and nanorefrigerant-oil mixture. Int. J. Refrigeration 32 (1), 114-123.

Edzwald, J.K., Malley, J.P., Yu, C., 1990. A conceptual model for dissolved air flotation in water treatment. Water Supply 8, $141-150$.

Henderson, K., Park, Y.G., Liu, L.P., Jacobi, A.M., 2010. Flow-boiling heat transfer of R-134a-based nanofluids in a horizontal tube. Int. J. Heat Mass Transfer 53 (5-6), 944-951.

Jensen, M.K., Jackman, D.L., 1984. Prediction of nucleate pool boiling heat transfer coefficients of refrigerant-oil mixtures. J. Heat Transfer 106, 184-190.

Jiang, W.T., Ding, G.L., Peng, H., Gao, Y.F., Wang, K.J., 2009. Experimental and model research on thermal conductivity of nanorefrigerant. HVAC\&R Res. 15 (3), 651-669.

Kedzierski, M.A., Kaul, M.P., 1993. Horizontal nucleate flow boiling heat transfer coefficient measurements and visual observations for R12, R134a, and R134a/ester lubricant mixtures. Proc. Int. Symp. Transport Phenom. Therm. Eng. 1, 111-116.

Kedzierski, M.A., 2009. Effect of diamond nanolubricant on R134a pool boiling heat transfer. Proceedings of MNHMT09 2nd ASME Micro/Nanoscale Heat \& Mass Transfer International Conference, December 18-21, Shanghai, China.

Kedzierski, M.A., Gong, M., 2009. Effect of CuO nanolubricant on R134a pool boiling heat transfer. Int. J. Refrigeration 32 (5), 791-799.

Liu, Z.H., Liao, L., 2008. Sorption and agglutination phenomenon of nanofluids on a plain heating surface during pool boiling. Int. J. Heat Mass Transfer 51, 2593-2602.

Malenkov, I.G., 1971. Detachment frequency as a function of size for vapor bubbles. J. Eng. Phys. Thermophys. 20 (6), 704-708.

Mermond, Y., Feidt, M., Marvillet, C., 1999. Thermodynamic and physical properties of mixture of refrigerants and oils. Int. J. Refrigeration 22, 569-579.

Nguyen, A.V., Ralston, J., Schulze, H.J., 1998. On modelling of bubble-particle attachment probability in flotation. Int. J. Miner. Process 53, 225-249.

Peng, H., Ding, G.L., Hu, H.T., Jiang, W.T., Zhuang, D.W., Wang, K.J., 2010. Nucleate pool boiling heat transfer characteristics of refrigerant/oil mixture with diamond nanoparticles. Int. J. Refrigeration 33 (2), 347-358.

Peng, H., Ding, G.L., Jiang, W.T., Hu, H.T., Gao, Y.F., 2009. Heat transfer characteristics of refrigerant-based nanofluid flow boiling inside a horizontal smooth tube. Int. J. Refrigeration 32 (6), 1259-1270.

Prasher, R., Bhattacharya, P., Phelan, P.E., 2006. Brownianmotion-based convective-conductive model for the effective thermal conductivity of nanofluids. J. Heat Transfer 128, 588-595.

Trisaksri, V., Wongwises, S., 2009. Nucleate pool boiling heat transfer of $\mathrm{TiO}_{2}-\mathrm{R} 141 \mathrm{~b}$ nanofluids. Int. J. Heat Mass Transfer 52 (5-6), 1582-1588.

Wang, K.J., Shiromoto, K., Mizogami, T., 2007. Experiment study on the effect of nano-scale particle on the condensation process. Proceeding of the 22nd International Congress of Refrigeration, August 20-26, Paper No. B1-1005.

Wang, R.X., Hao, B., Xie, G.Z., 2003. A refrigerating system using HFC134a and mineral lubricant appended with n-TiO2(R) as working fluids. In: Proceedings of the 4th International Symposium on HAVC. Tsinghua University Press, Beijing, China, pp. 888-892. 